\title{
Increasing access to consumer health organisations among patients with chronic disease - a randomised trial of a print-based intervention
}

\author{
Frances M. Boyle ${ }^{1}$, Allyson J. Mutch ${ }^{1}$, Julie H. Dean ${ }^{1}$, Marie-Louise Dick ${ }^{2}$ and Christopher B. Del Mar $^{3}$ \\ ${ }^{1}$ Social Science and Health Systems Academic Discipline Group, School of Population Health, \\ The University of Queensland, Herston, Australia \\ ${ }^{2}$ Discipline of General Practice, School of Medicine, The University of Queensland, Herston, Australia \\ ${ }^{3}$ Faculty of Health Sciences and Medicine, Bond University, Gold Coast, Australia
}

\begin{abstract}
Aim: To assess whether a print-based intervention led to increased contact with consumer health organisations ( $\mathrm{CHOs}$ ) by general practice patients with chronic disease. Background: $\mathrm{CHOs}$ can enhance people's capacity to manage chronic illness by providing information, education and psychosocial support. However, these organisations appear to be grossly under-utilised by patients and clinicians. Methods: A total of 276 patients completed a computer-assisted telephone interview before randomisation to an intervention $(n=141)$ or control $(n=135)$ group. The intervention consisted of mailed printed materials designed to encourage contact with a $\mathrm{CHO}$ relevant to the patient's main diagnosed chronic condition. Follow-up interviews were conducted 4 and 12 months later. Findings: Patients with conditions other than diabetes who received the intervention were twice as likely as those in the control group to contact a consumer health organisation during the 12 -month study period: $41 \%$ versus $21 \%(P<0.001)$. No such effect was found for diabetes patients, probably because of pre-existing high levels of contact with diabetes organisations. The intervention package received strong patient endorsement. Low-intensity interventions may be effective in improving access to $\mathrm{CHO}$ for patients with chronic disease.
\end{abstract}

Key words: chronic disease; non-profit organisations; patient education; primary care; self-management

Received 18 January 2010; accepted 22 November 2010; first published online 10 February 2011

\section{Introduction}

Encouraging patient self-management is fundamental to effective chronic illness care (Newman et al., 2004; Mensing et al., 2007) There are benefits to individuals and health systems from informed, empowered patients actively engaged

Correspondence to: Frances M. Boyle, Social Science and Health Systems Academic Discipline Group, School of Population Health, The University of Queensland, Level 2, Public Health Building, Herston Road, Herston, QLD 4006, Australia. Email: f.boyle@sph.uq.edu.au in their own care, including better quality of life; health status; clinical outcomes; and more efficient use of health resources (Lorig et al., 1999; Bodenheimer, 2005; Coulter and Ellins, 2007). In Australia and internationally, efforts to build people's chronic disease self-management capacity are high on the health policy agenda (Barr et al., 2003; Muir Gray, 2004; Newman et al., 2004; Coulter and Ellins, 2007; Fisher et al., 2007; Jordan and Osborne, 2007). As chronic disease selfmanagement has become increasingly mainstream (Osborne et al., 2008), various initiatives have emerged to provide patients with the information, 
skills and support needed for effective selfmanagement. These initiatives range from formal structured models through to informal models that operate largely outside the mainstream health system (Jordan et al., 2008). An example of the latter is consumer health organisations (CHOs) - non-profit or voluntary sector organisations that promote and represent the interests of users and/or carers (Allsop et al., 2004). These organisations can complement and reinforce selfmanagement aspects of clinical care by providing information, educational resources, psychosocial support and skill development for those with chronic illness and their carers at relatively low cost (Kessler et al., 1997; Von Korff et al., 1997; Wagner et al., 1999; Wilson, 1999; Fisher et al., 2007). CHOs offer an array of support options, including printed information, newsletters, telephone, Internet and face-to-face support, educational activities and links to other resources. They enable people to gain support and information at their own pace, at times and in formats that suit different needs and preferences.

Despite a shortage of systematic research into $\mathrm{CHOs,}$ data support their contribution to user outcomes, including psychosocial well-being, knowledge, mastery, coping and control (Trojan, 1989; Kyrouz et al., 2002; Boyle et al., 2009). However, research suggests CHOs are underutilised. Ellins and Coulter (2005) found only 5\% of people with a chronic disease had ever contacted a CHO while Gucciardi et al. (2006) found $3-13 \%$ of diabetes patients used support groups or organisations. Barriers to $\mathrm{CHO}$ use exist at patient, doctor and health system levels. Limited awareness among health professionals and patients of the existence, role and benefits of CHOs (Meissen et al., 2000) and lack of referral pathways (Von Korff et al., 1997; Carroll et al., 2000; Grant et al., 2000; Infante et al., 2004; Beesley et al., 2009) combine to impede access to these organisations.

Print-based materials directed at the patient level have been found to improve attendance at screening services and to be more cost effective than some higher intensity interventions (Shankaran et al., 2007) especially when they incorporate strategies to help the recipient achieve the desired behaviour change (Paul et al., 2004). To our knowledge, no prior study has evaluated such a strategy in terms of improving patient access to CHOs. We developed, implemented and evaluated a low-intensity print-based intervention designed to increase contact with $\mathrm{CHOs}$ by patients with chronic disease. This study reports on the efficacy of the intervention in terms of self-reported patient contact with $\mathrm{CHOs}$ and its acceptability to general practice patients.

\section{Methods}

\section{Study design and setting}

The study involved a randomised controlled trial of a print-based intervention designed to increase access to CHOs among general practice patients with diagnosed chronic disease. Patients were recruited by 18 general practitioners in Brisbane, Australia between February and July 2007. Patients who joined the study completed a computer-assisted telephone interview (CATI) soon after the entry to the trial and were then randomised to either the intervention or control group. Up to ten callbacks were made in an attempt to contact all eligible participants. The CATI method is well established and widely used data collection technique enabling trained interviewers to administer a pre-programmed questionnaire by telephone. Responses are automatically entered and coded during the interview offering significant advantages in terms of the timeliness and quality of data (De Vaus, 2002). Two follow-up CATIs were conducted approximately 4 and 12 months later. On average, each interview took between 10 and $20 \mathrm{~min}$. The study was approved by The University of Queensland's Behavioural and Social Sciences Ethical Review Committee.

\section{Participants}

Recruiting a representative sample of general practice patients with chronic disease involved a two-stage process: the recruitment of general practitioner (GPs), followed by the recruitment of patients. On the basis of initial power calculations, our goal was to recruit 650 eligible patients, 25 GPs each recruiting 26 patients. A feasibility study involving five GPs had indicated that this was readily achievable. Yet, recruitment proved more challenging in the actual study. Both the recruitment of GPs and their recruitment of patients were much slower than anticipated. 
Even with an expanded recruitment process, to complete the project within the required timeframe, it was necessary to cease recruitment at $57.5 \%$ of the target sample.

A random sample of 200 GPs was invited by mail to participate in the study but only eight GPs were recruited in this way. Chain referral, or snowball sampling, where respondents are asked to refer the researcher to one or more members of the target group was used to enlist further GPs. This resulted in 18 GPs who recruited a total of 374 patients to the study. During a specified recruitment period of up to three weeks, the participating GPs asked consecutive eligible patients if they would agree to join the study. Eligibility criteria were: age 18 years and over, sufficient English language skills to complete a telephone interview and a diagnosis of diabetes, arthritis, osteoporosis, ankylosing spondylitis, asthma, chronic hepatitis, haemochromatosis or renal disease based on standard diagnostic criteria.

\section{Randomisation}

Following the baseline telephone interview, patients were randomly assigned to receive by mail either the intervention package or a letter welcoming them to the study, and a gift pen. The randomisation procedure involved stratifying participants by their main health condition and using the computer tool Research Randomiser (Urbaniak and Plous, 1997-2009) to generate random numbers to determine the two groups. GPs were not made aware of the group to which the patient had been assigned and continued to provide usual care to all patients in the study.

\section{The intervention}

A print-based intervention package was designed as a low-cost method of reaching patients with chronic disease to increase their awareness of and access to a $\mathrm{CHO}$ relevant to their main diagnosed chronic condition. The intervention needed to be easily accessible to a wide cross-section of the general practice population, acceptable to patients and suitable for implementation in the general practice setting.

Development of the package was guided by three key principles: the incorporation of content and design characteristics; the use of behavioural strategies; and the use of marketing strategies
(Paul et al., 2004). Checklists outlining standard criteria for effective print communication materials were used to produce an information package that was easy to understand, act on and recall (Paul et al., 1997; Centers for Disease Control and Prevention, 1999). A comprehensive review of evidence for the effectiveness of printed education materials to increase patient participation in chronic disease management concluded that limited evidence of their effectiveness was at least partly due to printed materials not being developed through a rigorous process (Harris et al., 2005). Content and design characteristics include readability, ease of comprehension and presentation including font size and layout. They take account of low levels of health literacy that would be expected among subgroups of general practice patients with chronic disease (Gazmararian et al., 2003).

We paid particular attention to the incorporation of strategies to promote behaviour change and positively reinforce the desired behaviour as these have been shown to increase the effectiveness of printed health materials (Paul et al., 2004). Integrating this approach, the intervention package adopted an overall theme of getting in touch. Strategies to encourage recipients of our intervention package to get in touch with a $\mathrm{CHO}$, included: a personalised letter containing GP (one of the researchers) endorsement of a $\mathrm{CHO}$ relevant to the patient's main chronic condition and inviting contact with that $\mathrm{CHO}$; the $\mathrm{CHO}$ contact details; a reply-paid postcard addressed to the $\mathrm{CHO}$ requesting further information and resources; an outline of some of the potential personal benefits of CHOs to patients; and information that attempted to dispel some common misperceptions about CHOs (eg, to advise that $\mathrm{CHOs}$ provide a wide range of services, and that attendance at group meetings, while an option available at some CHOs, is not necessary). The package was compiled in a professionally designed compendium and included gifts of a pen and three greeting cards with envelopes for the recipient's personal use to reinforce the overall theme of getting in touch.

Finally, social marketing strategies were used to maximise the acceptability of the intervention to the target audience. The intervention package was developed in collaboration with various user groups to gain lay and expert input. Successive versions of the package were field tested with 
CHOs, their members, GPs and members of the general community. A graphic designer was employed to ensure a professional and highquality final product.

\section{Measures}

Data were collected using a self-report questionnaire that contained a mix of validated scales, items derived from studies reported in the literature and items customised for the purposes of the survey. Standard demographic questions were selected from the Australian National Health Survey (2001; 2004-2005; ABS, 2001; 2004), a triennial health survey undertaken by the Australian Bureau of Statistics.

The primary outcome was self-reported $\mathrm{CHO}$ contact during the 12-month study period. Questions about $\mathrm{CHO}$ contact were drawn from the literature and our prior research (Boyle et al., 2003; Coppa and Boyle, 2003). All participants were asked: 'Have you contacted $[$ a $\mathrm{CHO}$ relevant to their main diagnosed chronic condition]' since the previous interview (or ever, at the baseline interview). Those who had made contact were asked if they had engaged in any of the following nine activities: telephoned the $\mathrm{CHO}$; read the $\mathrm{CHO}$ newsletter or other printed materials; visited the $\mathrm{CHO}$ website; attended a CHO seminar; talked with other $\mathrm{CHO}$ members; attended a support group; used CHO services (eg, exercise classes, medical aids or counselling); used $\mathrm{CHO}$ information to raise awareness of the condition among others; or become a member of the CHO.

Participants in the intervention group were also asked a series of questions to evaluate patient perceptions, use and acceptability of the intervention package, including: whether they recalled receiving the package; whether they had looked at the package; and whether they had taken time to read the package. They were also asked to respond, using a 5-point scale ('strongly agree' to'strongly disagree'), to statements about the intervention package, including: 'was meant for someone like me'; 'contained useful information'; 'was something I would give to a friend or relative if relevant'; 'would have liked to have received the package sooner'; 'it would be a good idea for doctors to give the package to their patients'.

The questionnaire was piloted with members of the community prior to study commencement.

\section{Statistical analyses}

Analyses were performed on an intention to treat basis. Participants who dropped out of the study were included in the analysis. Missing responses on the primary outcome variable were recorded as 'no contact with the CHO'. On the basis of earlier work (Boyle et al., 2009), we expected people with diabetes to have had more prior contact with a $\mathrm{CHO}$ and this was borne out in the preliminary baseline data analysis. For this reason, planned a priori subgroup analyses were undertaken with diabetes analysed separately from the other main chronic condition categories. SPSS 15.0 (SPSS, 2006) was used for data analysis. $\chi^{2}$-tests were used to evaluate statistical significance of observed differences. A significance level of $P=0.05$ was applied.

\section{Results}

\section{Participant flow and response rates}

A total of 374 eligible patients were invited by 18 GPs to join the study, of whom 276 (73.8\%) completed the baseline interview (Figure 1). Baseline completers did not differ significantly from eligible non-completers in terms of sex, age or main chronic condition, as recorded by the recruiting GP. Randomisation resulted in 141 patients in the intervention group and 135 patients in the control group.

\section{Characteristics of the sample}

Musculoskeletal conditions (arthritis, osteoporosis and ankylosing spondylitis) were the main diagnosed chronic conditions for $52 \%$ of the 276 participants. This was followed by diabetes $(23 \%)$ and asthma $(15 \%)$ and smaller numbers with kidney disease $(6 \%)$, chronic hepatitis and haemochromatosis (both $2 \%$ ). The majority of study participants were women (66\%), married or living with a partner $(57 \%)$, with an average age of 63.89 years $(\mathrm{SD}=14.70$, median $=65.00)$. Most were Australian born (78\%) and only a small minority $(10 \%)$ spoke a language other than English at home. Nearly two-thirds were retired $(59 \%)$ and slightly more than half $(54 \%)$ had some form of private health insurance. The intervention and control groups and the diabetes and other conditions groups were evenly balanced across 


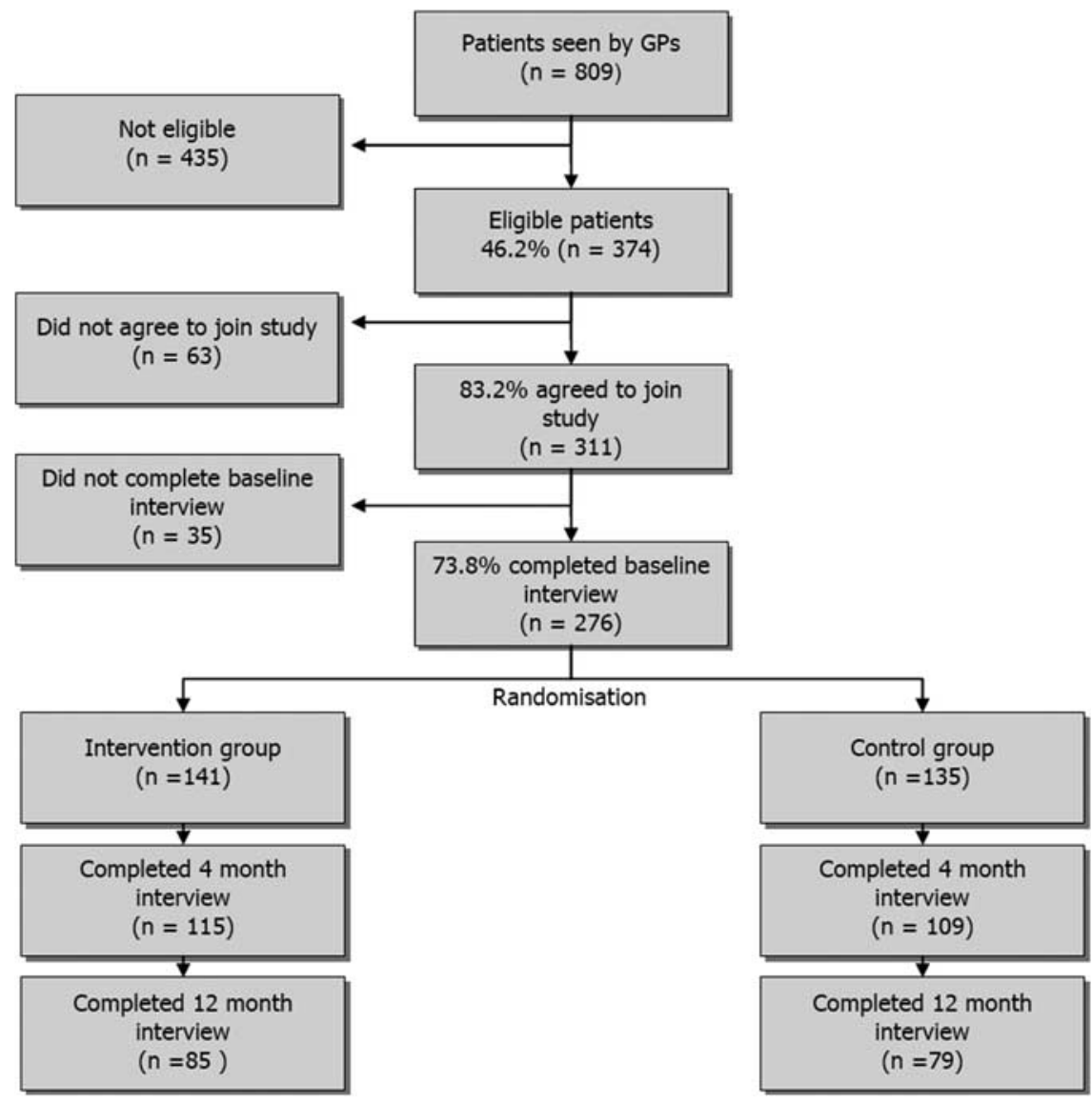

Figure 1 Participant flow and response rates

these baseline variables (Table 1). However, as expected, one notable difference was that patients with diabetes were significantly more likely to have had prior $\mathrm{CHO}$ contact when compared to other patients: $81 \%$ versus $11 \%(P<0.001)$.

\section{Use and perceptions of the intervention package}

Of 141 patients who were mailed an intervention package, 115 (82\%) completed the four-month interview, which included questions on use and perceptions of the package. Most $(81 \%)$ said they recalled receiving it, more than half $(61 \%)$ said they had taken time to look at it, and almost as many $(54 \%)$ said they had read its contents. The majority of those who had looked at the package agreed or strongly agreed that it: 'contained useful information' ( $71 \%$ ); 'was meant for someone like me' $(66 \%)$; and 'was something they would give to a friend or relative if relevant' $(81 \%)$. Almost half (46\%) said they would have liked to have received the package sooner and the vast majority $(91 \%)$ thought it would be a good idea for doctors to give the package to their patients.

At the 12-month interview, the $85(60 \%)$ intervention group members remaining in the study answered questions about their use of the package: $79 \%$ said they recalled the package, of whom $61 \%$ had kept it and $30 \%$ had referred to it again since the 4-month interview.

\section{Effect of the intervention on $\mathrm{CHO}$ use}

Table 2 compares the nature and amount of $\mathrm{CHO}$ contact post-intervention and during the 
Table 1 Sociodemographic characteristics of participants at baseline interview

\begin{tabular}{|c|c|c|c|c|c|c|}
\hline & \multicolumn{2}{|c|}{ Diabetes $(n=64)$} & \multicolumn{2}{|c|}{ Other conditions $(n=212)$} & \multicolumn{2}{|c|}{ Total $(n=276)$} \\
\hline & $\begin{array}{l}\text { Intervention } \\
\text { group } \\
(n=31) \\
n(\%)\end{array}$ & $\begin{array}{l}\text { Control } \\
\text { group } \\
(n=33) \\
n(\%)\end{array}$ & $\begin{array}{l}\text { Intervention } \\
\text { group } \\
(n=110) \\
n(\%)\end{array}$ & $\begin{array}{l}\text { Control } \\
\text { group } \\
(n=102) \\
n(\%)\end{array}$ & $\begin{array}{l}\text { Diabetes } \\
(n=64) \\
n(\%)\end{array}$ & $\begin{array}{l}\text { Other } \\
\text { conditions } \\
(n=212) \\
n(\%)\end{array}$ \\
\hline Gender (male) & $14(45.2)$ & $14(42.4)$ & $35(31.8)$ & $32(31.4)$ & $28(43.8)$ & 67 (31.6) \\
\hline Age: mean (years) ${ }^{a}$ & $63.61(12.57)$ & $61.85(13.74)$ & $65.31(14.03)$ & $63.11(16.27)$ & $62.70(13.11)$ & $64.25(15.14)$ \\
\hline Retired & 19 (61.3) & $18(54.5)$ & $69(62.7)$ & $57(56.4)$ & $37(57.8)$ & $126(59.7)$ \\
\hline Married or living with a partner & $21(67.7)$ & $27(84.4)$ & $60(54.5)$ & $50(49.5)$ & $48(76.2)$ & $110(52.1)$ \\
\hline Private health insurance & $15(48.4)$ & $20(60.6)$ & $57(51.8)$ & $58(56.9)$ & $35(54.7)$ & $115(54.2)$ \\
\hline Australian born & $22(71.0)$ & $26(78.8)$ & $88(80.0)$ & $78(77.2)$ & $48(75.0)$ & $166(78.7)$ \\
\hline Prior contact with $\mathrm{CHO}$ & $23(74.2)$ & $29(87.9)$ & $10(9.1)$ & $14(13.7)$ & 52 (81.3) & $24(11.3)$ \\
\hline
\end{tabular}

$\mathrm{CHO}=$ consumer health organisation

${ }^{\mathrm{a}}$ Mean (SD).

Table 2 Contact with $\mathrm{CHO}$ related to main health condition as reported at either the 4-month or 12-month interviews or both

\begin{tabular}{|c|c|c|c|c|c|c|c|c|}
\hline & \multicolumn{3}{|c|}{ Diabetes $(n=64)$} & \multicolumn{3}{|c|}{ Other $(n=212)$} & \multicolumn{2}{|c|}{ Total $(n=276)$} \\
\hline & $\begin{array}{l}\text { Intervention } \\
(n=31) \\
n(\%)\end{array}$ & $\begin{array}{l}\text { Control } \\
(n=33) \\
n(\%)\end{array}$ & $P$-value & $\begin{array}{l}\text { Intervention } \\
(n=110) \\
n(\%)\end{array}$ & $\begin{array}{l}\text { Control } \\
(n=102) \\
n(\%)\end{array}$ & $P$-value & $\begin{array}{l}\text { Diabetes } \\
(n=64) \\
n(\%)\end{array}$ & $\begin{array}{l}\text { Other } \\
(n=122) \\
n(\%)\end{array}$ \\
\hline One or more $\mathrm{CHO}$ activities & $20(64.5)$ & $26(78.8)$ & 0.20 & $45(40.9)$ & $21(20.6)$ & 0.001 & 46 (71.9) & $66(31.1)$ \\
\hline Telephoned $\mathrm{CHO}$ & $6(19.4)$ & $3(9.1)$ & 0.24 & $2(1.8)$ & $3(2.9)$ & 0.59 & $9(14.1)$ & $5(2.4)$ \\
\hline Read newsletter & $18(58.1)$ & $22(66.7)$ & 0.48 & $34(30.9)$ & $15(14.7)$ & 0.005 & $40(62.5)$ & $49(23.1)$ \\
\hline Visited website & $8(25.8)$ & $2(6.1)$ & 0.03 & $8(7.3)$ & $4(3.9)$ & 0.29 & $10(15.6)$ & $12(5.7)$ \\
\hline Attended seminar & $0(0)$ & $1(3.0)$ & 0.33 & $6(5.5)$ & $3(2.9)$ & 0.36 & $1(1.6)$ & $9(4.2)$ \\
\hline Talked with other $\mathrm{CHO}$ members & $4(12.9)$ & $4(12.1)$ & 0.93 & $4(3.6)$ & $1(1.0)$ & 0.20 & $8(12.5)$ & $5(2.4)$ \\
\hline Attended a support group & $1(3.2)$ & $1(3.0)$ & 0.96 & $0(0.0)$ & $0(0)$ & - & $2(3.1)$ & $0(0.0)$ \\
\hline Used $\mathrm{CHO}$ services & $11(35.5)$ & $20(60.6)$ & 0.04 & $2(1.8)$ & $3(2.9)$ & 0.59 & $31(48.4)$ & $5(2.4)$ \\
\hline Raised awareness & $6(19.4)$ & $13(39.4)$ & 0.08 & $20(18.2)$ & $8(7.8)$ & 0.03 & $19(29.7)$ & $28(13.2)$ \\
\hline Member of $\mathrm{CHO}$ & $13(41.9)$ & $18(54.5)$ & 0.31 & $2(1.8)$ & $1(1.0)$ & 0.61 & $31(48.4)$ & $3(1.4)$ \\
\hline
\end{tabular}

$\mathrm{CHO}=$ consumer health organisation .

course of the 12-month follow-up period based on sub-group analyses for 'diabetes' and 'other conditions'. As expected, those with diabetes had greater $\mathrm{CHO}$ contact across the board. There were no statistically significant differences between the diabetes intervention and control groups for most of the forms of $\mathrm{CHO}$ contact. However, there were two exceptions: those in the diabetes intervention group were significantly more likely to report using the $\mathrm{CHO}$ website than those in the diabetes control group; and diabetes controls were more likely to report using $\mathrm{CHO}$ services than those in the diabetes intervention group. For conditions other than diabetes, those in the intervention group were significantly more likely to report some form of contact with a $\mathrm{CHO}$ for their condition during the study: $41 \%$ compared with $21 \%(P=0.001)$. In particular, those who received the intervention package were more likely to have read a newsletter or other printed materials from the $\mathrm{CHO}$ to which they had been referred (31\% compared with $15 \% ; P=0.005)$ and to have discussed information received from the $\mathrm{CHO}$ with others in their social network (18\% compared to $8 \% ; P=0.03)$. Few study participants telephoned the $\mathrm{CHO}$ or 
talked with other $\mathrm{CHO}$ members and only a handful of people attended a $\mathrm{CHO}$ seminar or support group meeting.

\section{Discussion}

General practice patients who received a printbased intervention were significantly more likely to contact a $\mathrm{CHO}$ relevant to their main diagnosed chronic condition than those who did not receive the intervention. The exception was for patients with diabetes, most likely due to a ceiling effect reflecting their already high levels of $\mathrm{CHO}$ contact. There was strong patient endorsement of the intervention package indicating its acceptability as a health information resource for general practice patients with chronic disease.

Despite the potential benefits of CHOs (Trojan, 1989; Grant et al., 2000; Kyrouz et al., 2002; Boyle et al., 2009), studies have shown that only a small minority of people with chronic disease use these organisations (Ellins and Coulter, 2005; Gucciardi et al., 2006). In our study, diabetes presented a contrasting picture. The large majority (81\%) of patients with diabetes had a prior history of diabetes $\mathrm{CHO}$ contact and during the study's 12-month follow-up period, such contact occurred with similar and relatively high frequency for both the intervention (65\%) and control groups $(79 \%)$. The most likely explanation is that the NDSS (National Diabetes Services Scheme) established by the Australian Government in 1987 (AIHW, 2006) to provide subsidised services and products (such as insulin injecting devices and glucose monitors) and administered through the peak diabetes $\mathrm{CHO}$ (Diabetes Australia) has seen referral to this $\mathrm{CHO}$ become a relatively well accepted part of standard diabetes care.

Patients with conditions other than diabetes, where CHOs operate largely independent of medical services, conformed to the more commonly observed pattern: at baseline only a small minority (approximately 11\%) of those with a main condition such as arthritis, asthma or kidney disease had ever made contact with a CHO. Patients in this group who received the intervention were twice as likely as those who did not to contact a $\mathrm{CHO}$ recommended for their main diagnosed condition ( $41 \%$ compared to $21 \%$ ). That $21 \%$ of patients in the control reported making some form of contact during the 12-month study period may suggest a Hawthorne effect as this is higher than in other studies. Study participation and questions about $\mathrm{CHO}$ contact may have raised awareness and prompted some participants to make contact.

Of the 141 people who received the intervention package, $61 \%$ reported having at least looked at its contents and $41 \%$ reported having ultimately made some form of $\mathrm{CHO}$ contact. This broadly corresponds to previous observations related to the reach of self-management interventions (Fisher et al., 2007). Translated to a broader population of primary care patients with chronic illness, an increase in $\mathrm{CHO}$ contact of this magnitude would represent substantially greater $\mathrm{CHO}$ usage than at present.

Reading printed materials, including $\mathrm{CHO}$ newsletters was the most common form of $\mathrm{CHO}$ activity for study participants. This, together with use of $\mathrm{CHO}$ information to raise awareness about the chronic illness among others, was the main form of $\mathrm{CHO}$ activity undertaken by those in the non-diabetes group. Notably, very few engaged in other activities, such as telephoning the $\mathrm{CHO}$, attending support meetings or seminars or becoming a member. This finding suggests that many $\mathrm{CHO}$ users may choose and benefit from support at a distance, which contrasts with a commonly held view that equates $\mathrm{CHOs}$ with face-to-face meetings and ongoing contact. Patients with diabetes tended to engage more frequently in additional activities, such as using services and becoming a member. Those in the diabetes intervention group were significantly more likely to use the $\mathrm{CHO}$ website than those in the diabetes control group; and diabetes controls were more likely to use CHO services. These data are difficult to interpret: they may simply be anomalous, or the intervention package may have provided a prompt for people who were already engaged with the $\mathrm{CHO}$ to do something new (ie, seek out the $\mathrm{CHO}$ website).

To our knowledge, this is the first randomised controlled trial of a print-based educational strategy to increase the use of CHOs among people with chronic disease. Strengths of the study include the use of evidence-based principles (Paul et al., 2004) to guide the development of the intervention materials, the inclusion of a consecutive sample of general practice patients and a 
relatively long (12-month) follow-up period that acknowledged the decision to contact a $\mathrm{CHO}$ may take place over some time.

The study has a number of limitations. The results are based on self-report data. It is possible that some participants gave socially desirable responses leading to an overestimate of the actual number who contacted a $\mathrm{CHO}$. Our initial study protocol attempted to verify $\mathrm{CHO}$ contact, but doing so in a systematic and reliable way proved infeasible. People contacted the CHOs in different ways, including by telephone, Internet, physical attendance and return of the intervention package postcard. The demands placed on CHOs in attempting to establish and record the prompt for contact across different contact modes outweighed the benefits of doing so. We attempted to cross-check with $\mathrm{CHOs}$ the number of intervention package postcards received by study participants. The indication was that our results may have underestimated, rather than overestimated, the number of people who made contact.

A number of participants were lost to follow-up during the course of the study despite vigorous efforts to recontact all respondents. Nevertheless, our response rates of $81 \%$ and $59 \%$ at 4 and 12 months compare favourably with Grant et al. (2000) who reported a loss to follow-up of $32 \%$ at four months in their trial of a CHO referral strategy. Our response rates did not differ between the intervention and control groups or across different chronic conditions. The use of intention to treat analysis addressed the possibility that those who remained in the study were more motivated to contact a $\mathrm{CHO}$.

Our study aimed to increase the usage of $\mathrm{CHOs}$ and the primary outcome measure was confined to the $\mathrm{CHO}$ use. While demonstrating increased engagement with $\mathrm{CHOs,}$, it is not possible to draw conclusions about the outcomes of that contact. Previous research is consistent in demonstrating positive impacts for people who make contact with CHOs (Trojan, 1989; Grant et al., 2000; Kyrouz et al., 2002; Boyle et al., 2009) but further studies are needed to determine whether those who contact a $\mathrm{CHO}$ following a structured intervention to promote such contact experience positive outcomes in the longer term.

Finally, these findings are based only on patients who presented at a small number of general practices and who were able to complete a telephonic interview. Some patient groups, including those from culturally and linguistically diverse backgrounds, were under-represented in the study. Ideally, the study would have included a random sample of general practices. However, this was not possible and the challenges of initiating and maintaining GP involvement for the recruitment of patients have been well-documented in other studies (Perkins et al., 2008). Although it is possible that participating GPs were more sympathetic towards $\mathrm{CHOs}$ than the general population of GPs, exit interviews with the GPs following completion of the study indicated that only a limited number had referred patients to a $\mathrm{CHO}$ (Young et al., 2010).

\section{Conclusion}

Overall, the trial provides support for a printbased intervention as a mechanism to increase access to $\mathrm{CHOs}$ by reaching a large number of patients with chronic disease via the primary care setting. Further refinements, including stronger doctor endorsement, may amplify its impact. GPs are viewed as a highly trustworthy source and their advice increases the likelihood of patients acting on health information (Kreuter et al., 2000).

CHOs offer an existing and relatively low-cost community resource to support chronic disease self-management. Yet, this resource is often overlooked by both health professionals and patients. Low-intensity print-based interventions that are easily implementable in the primary care setting have the potential to increase $\mathrm{CHO}$ usage among people with chronic disease. Such interventions are likely to be most effective in relation to the chronic disease types in which there is normally little routine referral from the medical profession into CHOs. In the Australian setting, these include arthritis, kidney disease and asthma. Establishing better referral pathways from primary care to $\mathrm{CHOs}$ recognises the need to offer patients with chronic disease a wide range of support options that complement and extend standard clinical care.

\section{Acknowledgements}

The research reported in this paper is a project of the Australian Primary Health Care Research 
Institute, which is supported by a grant from the Australian Government Department of Health and Ageing. The information and opinions contained in it do not necessarily reflect the views or policy of the Australian Primary Health Care Research Institute or the Australian Government Department of Health and Ageing.

\section{References}

Allsop, J., Jones, K. and Baggott, R. 2004: Health consumer groups in the UK: a new social movement? Sociology of Health and Illness 26, 737-56.

Australian Bureau of Statistics. 2001: National health survey 2001. Canberra: Australian Bureau of Statistics.

Australian Bureau of Statistics. 2004: National health survey and national Aboriginal and Torres Strait Islander health survey 2004/2005. Canberra: Australian Bureau of Statistics.

Australian Institute of Health and Welfare. 2006: Australia's health 2006. Canberra: Australian Institute of Health and Welfare.

Barr, V.J., Robinson, S., Marin-Link, B., Underhill, L., Dotts, A., Ravensdale, D. and Salivaras, S. 2003: The expanded chronic care model: an integration of concepts and strategies from population health promotion and the chronic care model. Hospital Quarterly 7, 73-82.

Beesley, V.L., Janda, M., Eakin, E.G., Auster, J.F., Chambers, S.K., Aitken, J.F., Dunn, J. and Battistutta, D. 2009: Gynecological cancer survivors and community support services: referral, awareness, utilisation and satisfaction. Psycho-Oncology 19, 54-61.

Bodenheimer, T. 2005: Helping patients improve their healthrelated behaviors: what system changes do we need? Disease Management 8, 319-30.

Boyle, F.M., Posner, T.N., Del Mar, C.B., Mclean, J. and Bush, R.A. 2003: Self-help organisations: a qualitative study of successful collaboration with general practice. Australian Journal of Primary Health 9, 75-79.

Boyle, F., Mutch, A., Dean, J., Dick, M.-L. and Del Mar, C. 2009: Consumer health organisations for people with diabetes and arthritis: who contacts them and why? Health and Social Care in the Community 17, 628-35.

Carroll, J.C., Gray, R.E., Orr, V.J., Chart, P., Fitch, M. and Greenberg, M. 2000: Changing physicians' attitudes toward self-help groups: an educational intervention. Journal of Cancer Education 15, 14-18.

Centers for Disease Control and Prevention. 1999: Simply put: tips for creating easy-to-read print materials your audience will want to read and use. Georgia: Centers for Disease Control and Prevention.

Coppa, K. and Boyle, F.M. 2003: The role of self-help groups in chronic illness management: a qualitative study. Australian Journal of Primary Health 9, 68-74.
Coulter, A. and Ellins, J. 2007: Effectiveness of strategies for informing, educating, and involving patients. British Medical Journal 335, 24-27.

De Vaus, D. 2002: Surveys in social research. St Leonards, NSW: Allen \& Unwin.

Ellins, J. and Coulter, A. 2005: How engaged are people in their health care? Findings of a national telephone survey. Oxford: Picker Institute Europe.

Fisher, E.B., Brownson, C.A., O'toole, M.L., Anwuri, V.V. and Shetty, G. 2007: Perspectives on self-management from the diabetes initiative of the Robert Wood Johnson foundation. Diabetes Educator 33, S216-24.

Gazmararian, J.A., Williams, M.V., Peel, J. and Baker, D.W. 2003: Health literacy and knowledge of chronic disease. Patient Education and Counseling 51, 267-75.

Grant, C., Goodenough, T., Harvey, I. and Hine, C. 2000: A randomised controlled trial and economic evaluation of a referrals facilitator between primary care and the voluntary sector. British Medical Journal 320, 419-23.

Gucciardi, E., Smith, P.L. and Demelo, M. 2006: Use of diabetes resources in adults attending a self-management education program. Patient Education and Counseling 64, 322-30.

Harris, M., Smith, B. and Veale, A. 2005: Printed patient education interventions to facilitate shared management of chronic disease: a literature review. Internal Medicine Journal 35, 711-16.

Infante, F.A., Proudfoot, J.G., Davies, G.P., Bubner, T.K., Holten, C.H., Beilby, J.J. and Harris, M.F. 2004: How people with chronic illnesses view their care in general practice: a qualitative study. Medical Journal of Australia 181, 70-73.

Jordan, J.E. and Osborne, R.H. 2007: Chronic disease selfmanagement education programs: challenges ahead. Medical Journal of Australia 186, 84-87.

Jordan, J.E., Briggs, A.M., Brand, C.A. and Osborne, R.H. 2008: Enhancing patient engagement in chronic disease self-management support initiatives in Australia: the need for an integrated approach. Medical Journal of Australia 189, S9-13.

Kessler, R.C., Mickelson, K.D. and Zhao, S. 1997: Patterns and correlates of self-help group membership in the United States. Social Policy 27, 27-47.

Kreuter, M.W., Chheda, S.G. and Bull, F.C. 2000: How does physician advice influence patient behavior? Evidence for a priming effect. Archives of Family Medicine 9, 426-33.

Kyrouz, E., Humphreys, K. and Loomis, C. 2002: A review of research on the effectiveness of self-help mutual aid groups. In White, B.J. and Madara, E.J., editors, The self-help sourcebook: your guide to community and online self-help support groups, seventh edition. Cedar Knolls: American Self-Help Group Clearinghouse, 71-85.

Lorig, K.R., Sobel, D.S., Stewart, A.L., Brown, B.W., Bandura, A., Ritter, P., Gonzalez, V.M., Laurent, D.D. and Holman, H.R. 1999: Evidence suggesting that a chronic disease self-management program can improve 
health status while reducing hospitalization: a randomised trial. Medical Care 37, 5-14.

Meissen, G., Wituk, S., Warren, M.L. and Shepherd, M.D. 2000: Self-help groups and managed care: obstacles and opportunities. International Journal of Self Help \& Self Care 1, 201-10.

Mensing, C., Boucher, J., Cypress, M., Weinger, K., Mulcahy, K., Barta, P., Hosey, G., Kopher, W., Lasichak, A., Lamb, B., Mangan, M., Norman, J., Tanja, J., Yauk, L., Wisdom, K. and Adams, C. 2007: National standards for diabetes self-management education. Diabetes Care 30, S96-103.

Muir Gray, J.A. 2004: Self-management in chronic illness. Lancet 364, 14767-68.

Newman, S., Steed, L. and Mulligan, K. 2004: Selfmanagement interventions for chronic illness. Lancet 364, 1523-37.

Osborne, R.H., Jordan, J.E. and Rogers, A. 2008: A critical look at the role of self-management for people with arthritis and other chronic diseases. Nature Clinical Practice Rheumatology 4, 224-25.

Paul, C., Redman, S. and Sanson-Fisher, R. 1997: The development of a checklist of content and design characteristics for printed health education materials. Health Promotion Journal of Australia 7, 153-59.

Paul, C.L., Redman, S. and Sanson-Fisher, R.W. 2004: A cost-effective approach to the development of printed materials: a randomised controlled trial of three strategies. Health Education Research 19, 698-706.
Perkins, D., Harris, M., Tan, J., Christl, B., Taggart, J. and Fanaian, M. 2008: Engaging participants in a complex intervention trial in Australian general practice. $B M C$ Medical Research Methodology 8, 55.

Shankaran, V., Mckoy, J.M., Dandade, N., Nonzee, N., Tigue, C.A., Bennett, C.L. and Denberg, T.D. 2007: Costs and cost-effectiveness of a low-intensity patient-directed intervention to promote colorectal cancer screening. Journal of Clinical Oncology 25, 5248-53.

SPSS for Windows. 2006: Rel 15.0.0. Chicago: SPSS Inc.

Trojan, A. 1989: Benefits of self-help groups: a survey of 232 members from 65 disease-related groups. Social Science \& Medicine 29, 225-32.

Urbaniak, G. and Plous, S., 1997-2009: Research randomiser. USA: Social Psychology Network.

Von Korff, M., Gruman, J., Schaefer, J., Curry, S.J. and Wagner, E.H. 1997: Collaborative management of chronic illness. Annals of Internal Medicine 127, 1097-102.

Wagner, E.H., Davis, C., Schaefer, J., Von Korff, M. and Austin, B. 1999: A survey of leading chronic disease management programs: are they consistent with the literature? Managed Care Quarterly 7, 56-66.

Wilson, J. 1999: Acknowledging the expertise of patients and their organisations. British Medical Journal 319, 771-74.

Young, C., Mutch, A., Boyle, F. and Dean, J. 2010: Investigating referral pathways from primary care to consumer health organisations. Australian Journal of Primary Health 16, 260-67. 